\title{
Unusual presentation of the apparent mineralocorticoid excess, triggered by mild Cushing's disease in an adult
}

Zavratnik A. ${ }^{1}$, Završnik M. ${ }^{1}$, Kšela U. ${ }^{1}$, Homšak E. ${ }^{1}$, Sabati Rajić A. ${ }^{2}$, Gruson D. ${ }^{3}$, Pfeifer M. ${ }^{2}$

University Medical Centre Maribor, Maribor, Slovenia1, University Medical Centre Ljubljana, Ljubljana, Slovenia², Cliniques Universitaires St-Luc and Universite Catholique de Louvain, Brussels, Belgium ${ }^{3}$

\section{INTRODUCTION}

The syndrome of apparent mineralocorticoid excess (AME), a genetic disorder, resembles findings similar to those in primary aldosteronism, but aldosterone levels are low. AME is due to deficiency in the 11-betahydroxysteroid-dehydrogenase-enzyme-type-2 isoform (11-beta-HSD2), which normally converts cortisol to cortisone to prevent its mineralocorticoid activity at the aldosterone-sensitive sites. The deficiency in 11-betaHSD2 leads to marked elevation in net mineralocorticoid activity caused by unconverted cortisol.

\section{CASE REPORT}

50-years old woman was hospitalised after collapse. She had had arterial hypertension for 10 years (bisoprolol $5 \mathrm{mg} / \mathrm{d}$, perindopril/indapamide $8 / 2.5 \mathrm{mg} / \mathrm{d}$ ). At the presentation she was hypotensive $96 / 64$ $\mathrm{mmHg}$, mildly cushingoid, BMI $28 \mathrm{~kg} / \mathrm{m}^{2}$. Initial laboratory results: $\mathrm{s}-\mathrm{K} 2.44 \mathrm{mmol} / \mathrm{L}$, spot u-K $56 \mathrm{mmol} / \mathrm{L}$, blood pH 7.440. Patient's medical records revealed, that hypokalaemia had developed after 2001 and had been worsening gradually.

After correction of hypokalaemia primary aldosteronism was excluded (PRA $0.015 \mathrm{nmol} / \mathrm{L}$, aldosterone 0.22 $\mathrm{nmol} / \mathrm{L}$, after saline infusion aldosterone suppressed to $0.08 \mathrm{nmol} / \mathrm{L}$ ).

Cushing's disease was confirmed (s-ACTH: $5.31 \mathrm{pmol} / \mathrm{L}$, cortisol after standard two-day 2-mg dexamethasone test: $213 \mathrm{nmol} / \mathrm{L}$, late evening cortisol: $157 \mathrm{nmol} / \mathrm{L}$, pituitary MRI: $3 \times 4 \mathrm{~mm}$ microadenoma, IPSS: a central-to-peripheral plasma ACTH-gradient of 17.5, and left to right ACTH-ratio of 2.37 before CRH administration).

Since mild Cushing's disease couldn't explain severe hypokalaemia additional underlying cause was suspected. After exclusion of licorice ingestion and adrenocortical tumour, the AME was confirmed by undetectable free-cortison levels in urine measured by liquid-chromatography-tandem mass-spectrometry (LC-MS/MS) in two consecutive 24-hour urine samples (free cortisol 60.44 and $61.27 \mathrm{nmol} / \mathrm{L}$, free cortison two-times undetectable) (Figure 1).

Spironolactone was introduced. With the dose of $150 \mathrm{mg} / \mathrm{d}$ the patient became normokalaemic, and the hypertension was well controlled by additional bisoprolol $5 \mathrm{mg} / \mathrm{d}$ and perindopril $4 \mathrm{mg} / \mathrm{d}$.

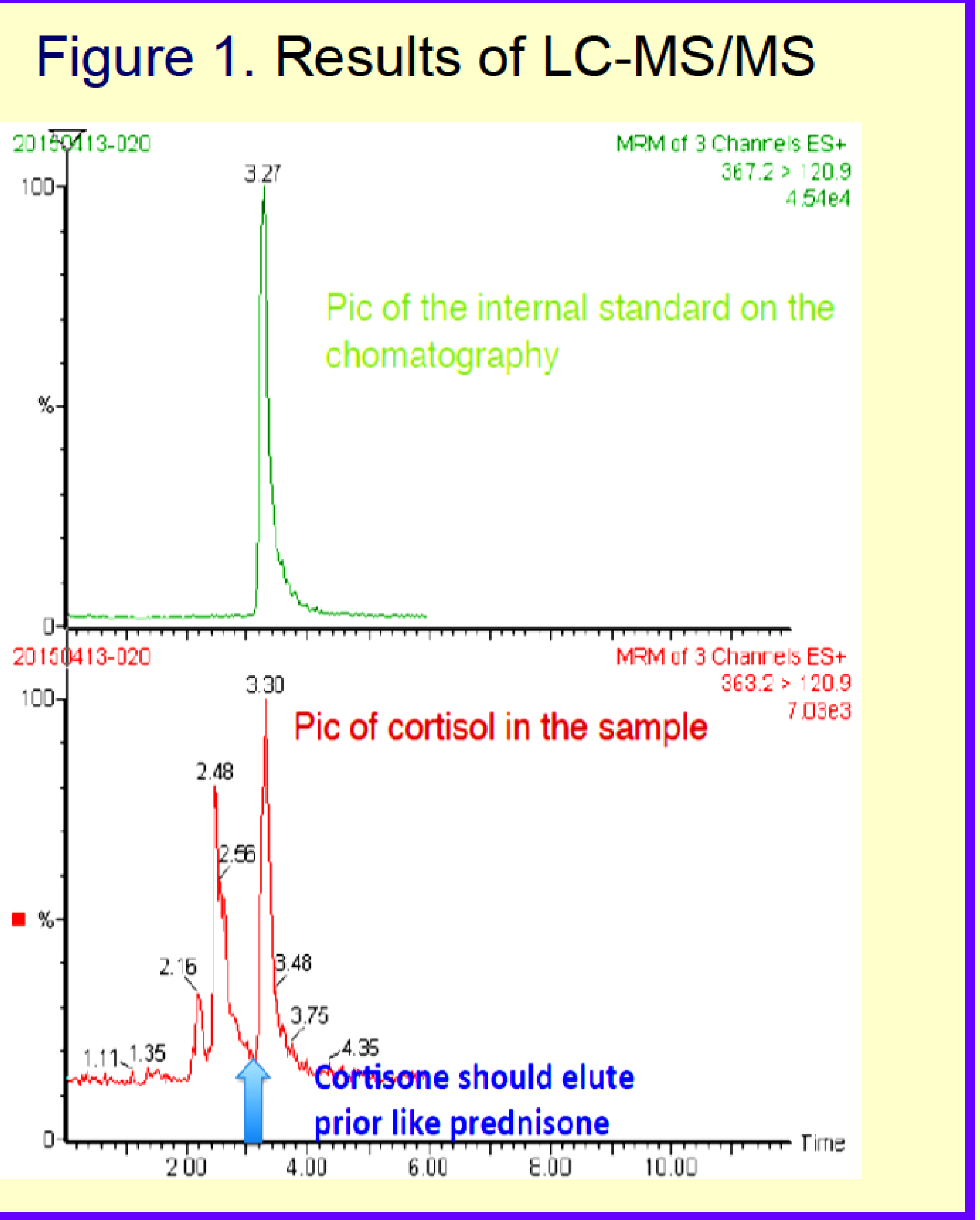

\section{CONCLUSIONS}

11-beta-HSD2 deficiency is a rare cause of hypertension and hypokalaemia.

Presented case report is of special interest showing that mild Cushing's disease has unmasked the underlying enzyme deficiency.

Genetic testing is in progress. Transsphenoidal microadenomectomy has been performed recently. Final results of post surgery hormonal testing are still awaiting. 